\title{
Trends in socio-economic
}

\section{inequalities in female mortality, \\ 2001-08. Intercensal estimates for \\ England and Wales.}

Brian Johnson and Alaa Al-Hamad, Office for National Statistics

\section{Abstract \\ Background}

This article presents estimates of annual mortality rates for women of working age by the National Statistics Socio-economic Classification (NS-SEC) for the period 2001 to 2008. Until recently, it was possible to produce such mortality rates only at the time of the decennial census when populations are enumerated by occupation and NS-SEC. In 2010, ONS published annual intercensal male mortality rates using the Labour Force Survey (LFS) to provide population estimates by age and NS-SEC. This article produces the corresponding estimates for women aged 25 to 59.

\section{Methods}

The LFS was used to estimate female populations by age and NS-SEC for each year between 2001 and 2008. Numbers of deaths were obtained from death registrations. For both deaths and populations, the combined method of NS-SEC classification was used, whereby the most advantaged of a married woman's and her husband's NS-SEC was used to assign the woman to an NS-SEC class. Single women were classified according to their own NS-SEC. Age-standardised mortality rates were derived for each NS-SEC class by year and a number of measures of inequality estimated for each year so that any trends could be identified.

\section{Results}

While overall mortality rates for women declined over the period, this was not true for all NS-SEC classes. Managerial and professional occupations and Routine occupations experienced a statistically significant decline in mortality rate over the period. There was no clear trend for the other classes. Absolute measures of inequality showed no clear trend over the period, but relative inequalities tended to increase. Routine occupations had the greatest decline in mortality rate over the period of approximately five deaths per 100,000 per annum. 


\section{Conclusions}

Socio-economic inequalities in the mortality rates of women appeared to increase between 2001 and 2008. However, the results for women were not as clear as for men with four out of the seven analytic NS-SEC classes not having a statistically significant downward trend in mortality. The degree of annual volatility in the measures suggests that at the current low levels of mortality of working age women, the LFS could not be used to provide population denominators below the national level. Possibly, three-year moving averages would be better trend indicators, but this would reduce the timeliness of the data to some extent. 


\section{Contents}

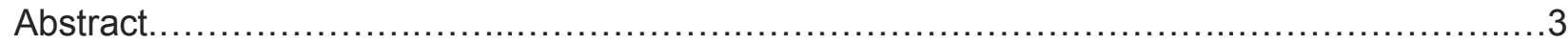

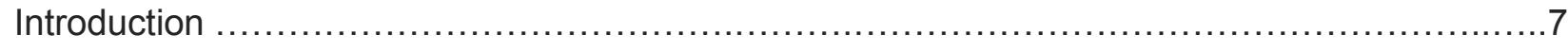

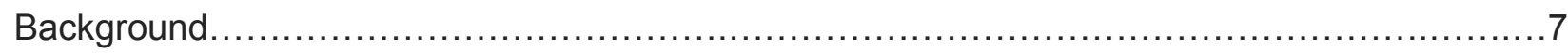

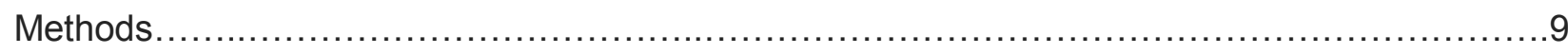

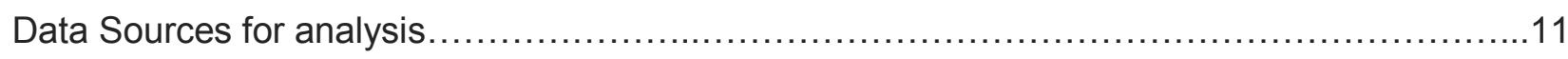

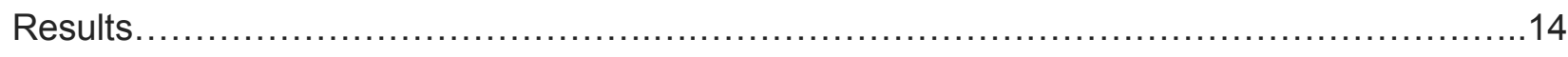

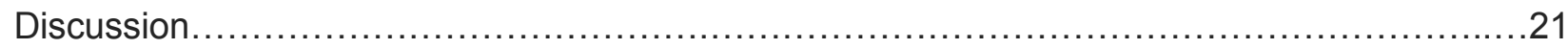

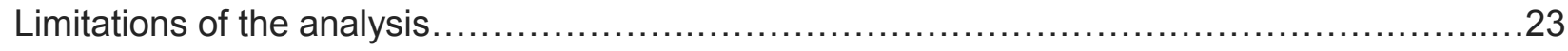

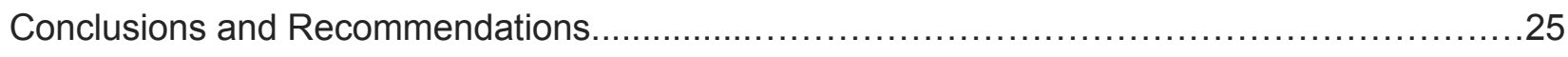

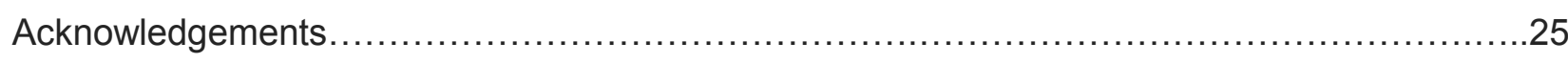

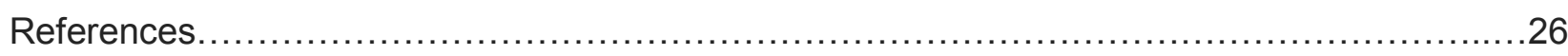

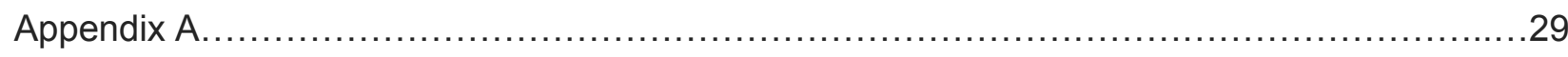

\section{List of Figures}

Figure 1 Age-standardised mortality rates by seven-class NS-SEC for 2001-08, women

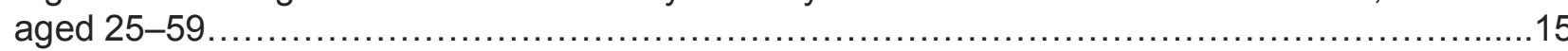

Figure 2 Age-standardised mortality rates by three-class NS-SEC for 2001-08, women

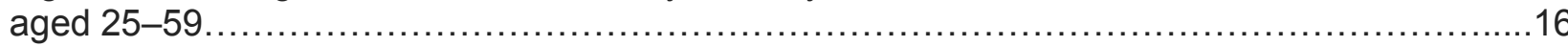

Figure 3 Measures of absolute inequalities in mortality rates of NS-SEC classes by year,

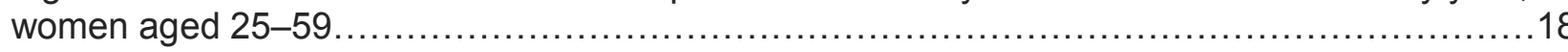

Figure 4 Measures of relative inequalities in mortality rates of NS-SEC classes by year,

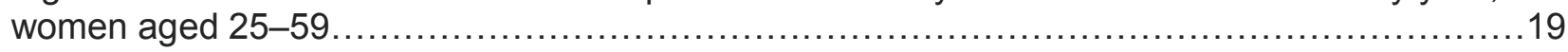

Figure 5 Three-year simple moving averages of age-standardised mortality rates by NS-

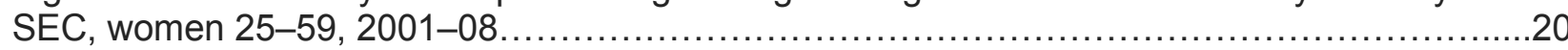




\section{List of Tables}

Table $1 \quad$ Age-standardised mortality rates by seven-class NS-SEC for 2001-08, women aged $25-59$......

Table 2 Age-standardised mortality rates by three-class NS-SEC for 2001-08, women

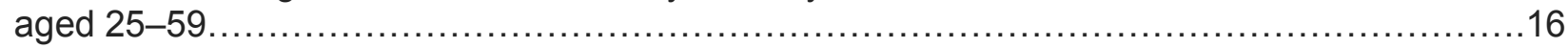

Table 3 Estimated annual decrease in mortality rate by NS-SEC, women aged 25-59...17 Table 4 Measures of absolute inequalities in mortality rates of NS-SEC classes by year,

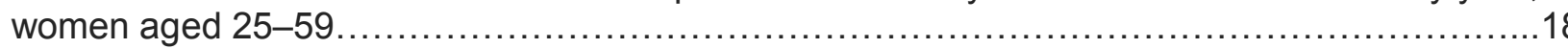

Table 5 Measures of relative inequalities in mortality rates of NS-SEC classes by year,

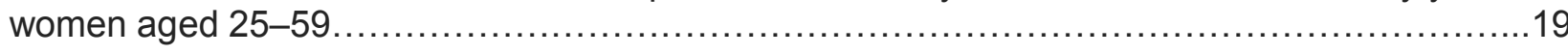

Table A1 Raw LFS population counts by NS-SEC and steps involved in reallocating residual

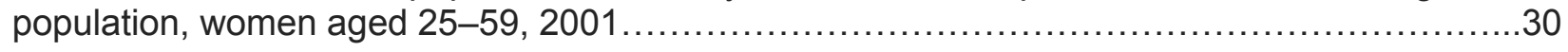

Table A2 Revised population counts by NS-SEC after adjustments, women aged 25-59,

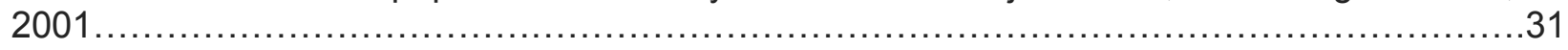

Table A3 2001-08 Study number of deaths by combined NS-SEC classification, women aged

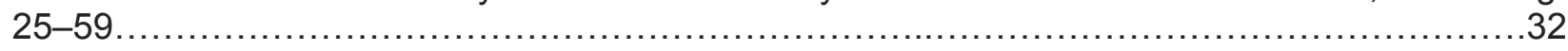

Table A4 2001-08 LFS Study populations (person years at risk) by combined1 NS-SEC classification, women aged $25-59$. 


\section{Introduction}

Socio-economic inequalities in mortality have been observed and documented for a century in England and Wales. The Black Report (1980), the Acheson Report (1998), and most recently the Strategic Review of Health Inequalities (The Marmot Review 2010) all observed a social gradient in health and recommended action to tackle it.

The monitoring of progress in reducing these inequalities requires timely measures which are capable of regular updating. The conventional method for measurement of inequalities in mortality, since the derivation of Registrar General's social class, involved the use of occupation recorded on death registrations and those recorded at a census in order to estimate the mortality rates for different occupational groups. Among the limitations of this method is the fact that it can only be used once every ten years - at the time of the decennial census. An additional drawback for measuring the social inequality among women is that registrars did not always record occupation for married women.

This article represents an attempt to overcome these problems. It presents, for women aged 2559 , estimated annual mortality rates by the National Statistics Socio-economic Classification (NSSEC) for the years 2001-2008, along with a number of measures of inequality in mortality derived from these rates. The study uses a methodology developed by the Office for National Statistics (ONS) that uses the Labour Force Survey (LFS) to provide estimates of the population at risk by NS-SEC. It also uses a combined NS-SEC classification for married women based on the most advantaged NS-SEC class of a woman and her husband. It makes possible the comparison of recent trends in mortality of working age women by NS-SEC with those of men over a similar period.

The study also further tests the suitability of the LFS for monitoring socio-economic inequalities on an annual basis.

\section{Background}

Social inequalities in mortality among men have been studied continuously since the early Twentieth Century. Corresponding studies of female mortality have been much more rare, as a result of women's historically weaker ties to the labour market and the related difficulties in accurately classifying women to a socio-economic class based on occupation. However, some studies have attempted to measure inequalities in mortality among women. The Black Report (1980) estimated that the death rate for women in the most disadvantaged social class was two and a half times higher than the comparable rates for women in the most advantaged social class. White et al (2003) reported similar inequalities for the 1990s, with women in social classes IV and $\mathrm{V}$ having a mortality rate approximately one and a half times that of women in classes I and II. Johnson (2011) estimating trends in life expectancy by NS-SEC using the ONS Longitudinal Study found a fairly consistent difference in life expectancy at birth between Higher managers and professional women (the most advantaged) and Routine workers (the least advantaged) of approximately four years between the periods 1982-86 and 2002-06. This study did not provide any sign of a narrowing in the gap between the most and least advantaged women over time. 
Owing to the difficulties associated with recording of womens' occupation, studies using nonoccupational measures have been attempted for women. For women of working age, mortality differences by housing tenure and access to cars were similar to those for men (Goldblatt,1990). The Department of Health (2009), using an area based deprivation measure to compare mortality in the most deprived areas with the mean mortality rate for England, found an increasing gap between the two, both in absolute and relative terms between 2000-02 and 2006-08.

With the introduction of the new socio-economic classification, NS-SEC, it was necessary to estimate female mortality by NS-SEC as had been done for men by White et al (2007). In order to do this, a method of classification had to be used which was based on occupation, but was capable of overcoming the worst effects of the under-reporting of married women's occupation on death and the weaker ties to the labour market of some women compared to men. Langford and Johnson (2009) used a 'combined' measure of the woman's occupation-based class and that of her husband, classifying the woman by the most advantaged class of the two. This concept was based on the labour market 'dominance' approach suggested by Erikson (1984), and assumes that the life chances of individuals in a family unit are more likely to be aligned with that of the most advantaged individual in that unit. Unmarried women were classified according to their own occupation.

Using this measure for deaths over period 2001-03 and the 2001 Census to provide populations by age group on the same basis, a mortality ratio of 2.6 times was found for the Routine occupations compared to the Higher managerial and professional occupations (the least relative to the most advantaged). This was a similar ratio to that obtained for men over the same period.

This method could be used only for the period close to the decennial census. Given the need for more timely and continuous measures of health and specifically mortality inequality, the LFS was considered as a substitute for the census as a provider of population denominators by age and NS-SEC. The standard LFS survey is conducted quarterly and in addition, there are annual versions which include booster samples. Thus, if the LFS sample could be shown to be adequate for this purpose, annual estimates of mortality rates by NS-SEC class and of associated inequalities could be produced.

The approach taken was first to compare the age-standardised mortality rates by NS-SEC for men obtained using the LFS with those using the census for the years 2001-03, (Johnson and Langford, 2010). While there were statistically significant differences between the two sets of results for certain NS-SEC classes, the overall pattern and the scale of inequality were very similar. Following this, a recent article (Langford and Johnson 2010) used LFS based population data to provide annual denominators by age and occupation in order to estimate male mortality rates by NS-SEC for each year between 2001 and 2008.

This article provides corresponding estimates of mortality rates for women of working age over the same period. 


\section{Methods}

This section describes the measure of socio-economic class along with the data sources used and the outcome measures adopted in this article.

\section{The National Statistics Socio-economic Classification}

In this article the National Statistics Socio-economic Classification (NS-SEC) was used as a measure of socio-economic position. It was developed during the 1990s with the aim of replacing both the Registrar General's Social Class and the National Statistics Socio-economic Groups, with a measure having a proper conceptual and theoretical basis (Rose and Pevalin (Eds), 2003). The conceptual basis for the NS-SEC is the structure of employment relations operating in modern developed economies. Occupations are differentiated in terms of reward mechanisms, promotion prospects, autonomy and job security. The most advantaged NS-SEC classes (Higher managerial and professional) typically exhibit personalised reward structures, have good opportunities for advancement, relatively high levels of autonomy within the job, and are relatively secure. These attributes tend to be reversed for the most disadvantaged class (Routine).

The operational categories of the NS-SEC can be derived by three principal methods, full, reduced and simplified depending on the data available. The full NS-SEC requires occupational information coded to the standard occupational classification 2000 (SOC 2000), details of employment status and the size of the organisation. (In this context, employment status refers to whether the person is (or was) an employer or employee, and if an employee, whether they are (or were) a manager or supervisor. It does not relate to whether they were employed or unemployed). The reduced NS-SEC requires occupational classification and details of employment status. The simplified NS-SEC is derived from occupation alone. For the purpose of this article, since the size of the organisation is not recorded on the death register, the reduced method was used to derive NS-SEC throughout.

For the purpose of analysis, NS-SEC is nested so that the operational categories can offer maximum flexibility in terms of the different collapses possible. Box 1 presents the eight-class version of the NS-SEC.

NS-SEC can also be collapsed into three analytic classes. This is known as 'condensed' NS-SEC and comprises:

1. Professional and managerial (consisting of analytic classes 1.1,1.2 and 2 in Box 1)

2. Intermediate (consisting of analytic classes 3 and 4 in Box 1)

3. Routine and manual (consisting of analytic classes 5, 6 and 7 in Box 1)

This is the conventional terminology for these aggregate groups (Rose and Pevalin (Eds), 2003), and the interpretation of 'manual' in the 'Routine and manual' category is clearly different to that used in the Registrar General's social class schema, which consisted of a hierarchy where all non-manual occupations ranked above manual ones. 
The analysis in this study combined classes 1.1 and 1.2 to produce a seven-class framework and also used Condensed NS-SEC, since more aggregative groups possess more statistical robustness, at the cost of masking some of the changes revealed by the more granular schema.

Those without a validly recorded occupation were excluded from this analysis, since they were composed of a disparate range of people and are often coded according to different rules at death registration to those applied by the census or the LFS.

\section{Box 1 National Statistics Socio-economic Classification Analytic classes}

\section{Analytic classes}

Eight class version

$\begin{array}{ccl}\begin{array}{c}\text { Higher } \\ \text { managerial } \\ \text { and } \\ \text { professional } \\ \text { occupations }\end{array} & 1.1 & \begin{array}{l}\text { Large employers and higher } \\ \text { managerial }\end{array} \\ 2 & \begin{array}{l}\text { Higher professional } \\ \text { Lower managerial and } \\ \text { professional }\end{array} \\ 3 & \begin{array}{l}\text { Intermediate } \\ 4\end{array} \\ 5 & \begin{array}{l}\text { Small employers and own } \\ \text { account workers } \\ \text { Lower supervisory and } \\ \text { technical }\end{array} \\ 5 & \text { Semi-routine } \\ 7 & \text { Routine }\end{array}$

Non-occupied

ONS (2007)

\section{Examples of occupations include}

Senior officials in national and local government; directors and chief executives of major organisations; officers in the armed forces

Civil engineers, medical practitioners, physicists, geologists, IT strategy and planning professionals, legal professionals, architects

Teachers in primary and secondary schools, quantity surveyors, public service administrative professionals, social workers, nurses, IT technicians

NCOs and other ranks in the Armed Forces, graphic designers, medical and dental technicians, local government clerical officers, counter clerks

Hairdressing and beauty salon proprietors, shopkeepers, dispensing opticians in private practice, farmers, self-employed taxi drivers

Bakers and flour confectioners, screen-printers, plumbers, electricians and motor mechanics employed by others, gardeners, rail transport operatives

Pest control officers, clothing cutters, traffic wardens, scaffolders, assemblers of vehicles, farm workers, veterinary nurses and assistants, shelf fillers

Hairdressing employees, floral arrangers, sewing machinists, van, bus and coach drivers, labourers, hotel porters, bar staff, cleaners and domestics, road sweepers, car park attendants

Never worked, Long-term unemployed, Full time students, Occupation inadequately described and Unclassified for other reasons 


\section{Data Sources for analysis}

\section{Mortality data}

Death registration records were used to identify deaths for working age females (25-59), registered in England and Wales in each of the calendar years 2001 to 2008 together with their occupational classification. However, while for men there is good recording of occupational details at death that allows clear allocation of an NS-SEC occupied class, this is not the case for women. There is a substantial degree of under reporting of the occupations of women at death which makes it more difficult to assign them to an NS-SEC occupied class. Therefore, for females in this analysis it was thought to be most appropriate to use a 'combined' classification whereby a non-married woman is assigned an NS-SEC class on the basis of her own occupation and employment status and a married woman is assigned the most advantaged NS-SEC class of either herself or her husband. (Non-married partners were not recorded on death certificates during this period and so only the spouse's occupation was used in assigning NS-SEC, if applicable).

The mortality data used in this analysis also had to be adjusted to correct for the misallocation of deaths identified by White et al (2007). This study found that a number of deaths were likely to have been misclassified as NS-SEC class 3 (Intermediate) rather than class 2 (Lower managerial and professional). This was because some death registration entries failed to record that the individual concerned had a supervisory role. Examination of the ONS Longitudinal Study (LS) revealed that there was evidence from the census that a proportion of these individuals had been supervisors and therefore should have been classified as NS-SEC class 2. A similar analysis was undertaken for women by Langford and Johnson (2009), and the resultant proportional adjustments between the two classes were used throughout the current study, in the absence of any new relevant data.

The same study also observed that for 19 per cent of female deaths between the ages of 25 and 59 , insufficient occupational details were available to allow classification by combined NS-SEC classification. Using the Longitudinal Study, in a sample of 158 women who were unclassified by occupation at death, the NS-SEC classification could be determined by reference to their census records. The distribution of this sample then was used to reallocate the unclassified women across NS-SEC classes. For more detail on the process of adjustment of mortality data see Langford and Johnson (2009, page10).

The total number of deaths by combined NS-SEC is shown in the Appendix, Table A3 


\section{Population data}

The England and Wales female population figures used in this analysis were obtained using annual 2010 weighted LFS datasets, for the years 2001-08 and the ONS mid-year population estimates used to provide control totals by age groups.

The LFS data is a continuous sample survey carried out throughout the United Kingdom to provide information on the UK labour market. It collects detailed data on occupation for a sample of approximately 53,000 private addresses throughout the United Kingdom each quarter. The data are available at national, regional and local authority levels. Response rates were around 65 per cent (see Limitations of the analysis). The results from the survey are weighted to ONS estimates of the private household population (ONS 2010).

Adjustments were made to the population figures for the effect of health selection out of the labour market. This is a phenomenon whereby those already in poor health are less likely to record an occupation and this may have a disproportionate effect across the NS-SEC classes (Fox et al, 1985). This can be adjusted for using the LS, since sample members who had no recorded occupation at the 2001 Census could be traced back to the 1991 Census. A high proportion of these, especially in the upper age groups of the study population, did have an occupation at 1991 and therefore could be assigned to an NS-SEC class accordingly.

The exact process of adjustment for health selection follows that described for men in Johnson and Langford (2010). The difference between the ONS mid-year populations for each five year age band (the control totals) and the population in that age group assigned to an NS-SEC class according to the LFS, was defined as the residual population. This residual was split into two groups. The first was obtained by estimating the percentage of the overall mid-year population remaining unclassified by NS-SEC following the health selection adjustments. The remainder of the residual population was reallocated across the 'analytic' or occupation-based NS-SEC classes based on the proportions derived from the LS as described above and shown in Langford and Johnson (2009) for the years 2001-03. For more details on health selection adjustments in this context, see the Appendix to this article.

The total population numbers of woman aged $25-59$ by NS-SEC over the study period, based on LFS estimates are shown in the Appendix, Table A4.

\section{Outcome measures}

To compare mortality between the different NS-SEC classes, for each year, age-standardised mortality rates for each NS-SEC were calculated, using the European standard population. Confidence intervals for each mortality rate were also calculated, taking into account the variance of the death counts and the sampling variance of the LFS population estimates.

To examine inequalities, two types of indicators were considered, absolute and relative. Absolute indicators measure the difference between the least and most advantaged in terms of the number of deaths per head of population per annum. Relative indicators measure inequality as a ratio of the mortality rate of the least to the most advantaged. Box 2 provides more explanation of the difference between absolute and relative measures of inequality. 


\section{Box 2 The difference between absolute and relative measures of inequality}

To illustrate the difference between the two types of measures, consider the following hypothetical example where the mortality rate for the Routine class (NS-SEC class 7) is 500 deaths per 100,000 person years, and the mortality rate for the Higher managerial and professional class (NS-SEC class 1) is 100 deaths per 100,000 person-years. Imagine that the rates change to 450 deaths and 75 deaths respectively. In absolute terms of deaths per 100,000 person years, the gap between the most and least advantaged classes is 400 in the first instance (500-100) and 375 in the second instance (450-75). This implies that the inequality, in terms of the absolute number of deaths involved, has reduced.

In the same hypothetical example, however the deaths in the Routine class are five times as high (500/100) as those in the more advantaged class. In the second instance the relative inequalities imply that mortality rates of the disadvantaged are now six times as high (450/75). So inequality in relative terms has become larger.

In this example the reduction in mortality rates for the more advantaged class, the Higher managerial and professional class, has been small in terms of the number of deaths (25 deaths) compared to the reduction achieved in the Routine class (50 deaths). But because the more advantaged class starts at a much lower level the percentage improvement is large $(25 \%)$ compared to the percentage improvement in the Routine class $(10 \%)$. Thus because the more advantaged class is at a lower level it is harder to achieve similar percentage reductions in the mortality rate of the more disadvantaged class, and hence maintain the relative gap.

To explore the different potential interpretation of absolute and relative measures of inequalities, three indicators of absolute inequality were calculated. The first indicator was simply the difference in mortality rates between the least and most advantaged NS-SEC classes, using the broad three-class schema. This indicator was the difference between the mortality rates for the 'Managerial and professional' class and the 'Routine and manual' class. The second indicator adopted a similar approach, but was based on the more detailed seven-class version of NS-SEC and was therefore the difference between the mortality rates of the Routine class and the Higher managerial and professional class (NS-SEC class 7 and 1). The third indicator is the slope index of inequality (SII). This indicator uses all of the available data to model the difference between mortality rates of those with the hypothetically lowest and highest socio-economic position. 
Three indicators of relative mortality to compare the position of the more disadvantaged groups relative to the more advantaged group were also calculated. The first was the ratio of the mortality rate of the least to the most advantaged NS-SEC class, using the broad three-class schema. Thus the first indicator was the ratio of the mortality rates of the Routine and manual class to that of the Managerial and professional class. The second indicator was similar, but based on the more detailed version of NS-SEC and was the ratio of the mortality rates of the 'Routine' class and the 'Higher managerial and professional' class (NS-SEC classes 7 and 1). The third indicator is an analogous measure to the SII, the relative index of inequality (RII). This indicator takes into account the intervening classes, in addition to the most and least advantaged classes.

The method of calculation of the SII and RII is shown in Box 3.

\section{Box 3 The calculation of Slope and Relative Index of Inequality ( SII and RII )}

These indices were calculated following the method described in Sergeant and Firth (2006) and previously used by Kunst and Mackenbach (1994) among others.

The socio-economic groups were ordered, from lowest to highest socio-economic status. The fraction of the population in class i or lower was calculated $\left(c_{i}\right)$, thus $c_{i}$ represents the cumulative proportion in class $\mathrm{i}$ or lower. Each group was then assigned a median social rank

$x=\left(c_{i+} c_{i-1}\right) / 2$

The mortality rate for each class, $\mathrm{y}$, was then regressed against the median social rank, using group population totals as weights, yielding a straight line estimate, $y=a+b x$

The slope index of inequality(b) represents the difference in mortality rates between the highest and lowest on the socio-economic scale. (As calculated, $b$ is negative, but has been reported as positive for ease of presentation.) The RII was then calculated $a s a /(a+b)$ and thus represents the ratio of mortality rates of the least advantaged to the most advantaged.

\section{Results}

The age-standardised mortality rates by year and seven-class NS-SEC are shown in Table 1 and Figure 1 and by three-class NS-SEC in Table 2 and Figure 2. 


\section{Figure 1 Age-standardised mortality rates by seven-class NS-SEC for 2001-08, women aged 25-59}

England and Wales

Rate per 100,000 person years

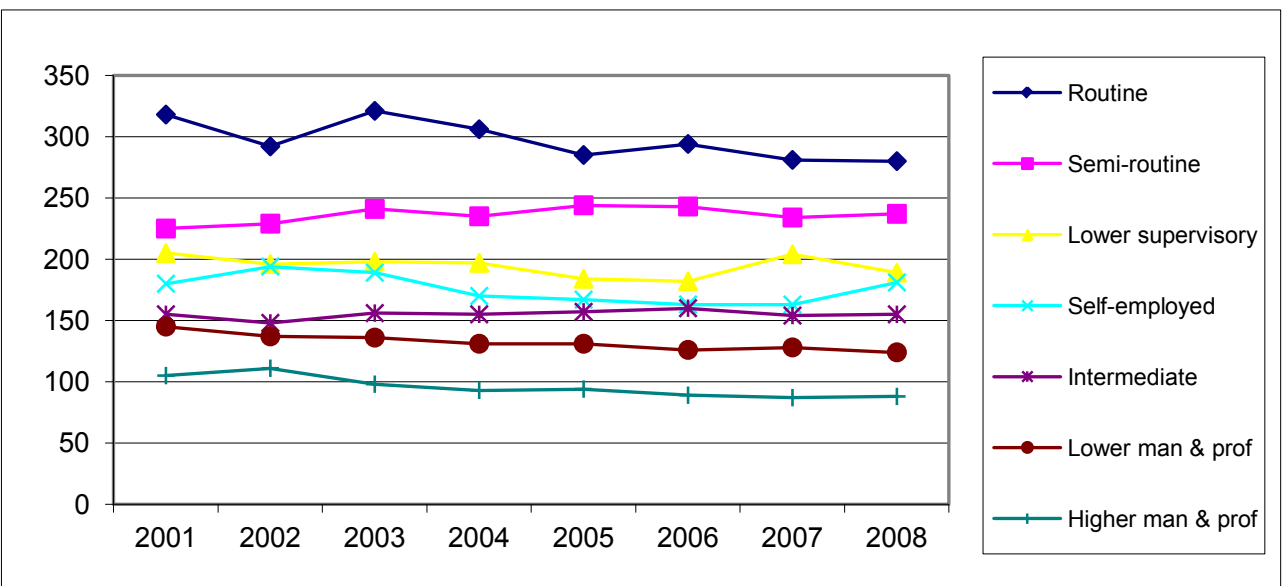

\section{Table 1 Age-standardised mortality rates by seven-class NS-SEC for 2001-08, women aged 25-59}

\begin{tabular}{|c|c|c|c|c|c|c|c|}
\hline & \multicolumn{7}{|c|}{ NS-SEC analytic class } \\
\hline & $\begin{array}{r}\text { Higher } \\
\text { managerial } \\
\& \text { prof }\end{array}$ & $\begin{array}{r}\text { Lower } \\
\text { managerial } \\
\& \text { prof }\end{array}$ & Intermediate & $\begin{array}{r}\text { Self- } \\
\text { employed }\end{array}$ & $\begin{array}{r}\text { Lower } \\
\text { supervisory }\end{array}$ & $\begin{array}{r}\text { Semi- } \\
\text { Routine }\end{array}$ & Routine \\
\hline \multirow{2}{*}{2001} & 105 & 145 & 155 & 180 & 205 & 225 & 318 \\
\hline & 101,110 & 141,150 & 148,162 & 170,189 & 195,214 & 216,235 & 301,334 \\
\hline \multirow[t]{2}{*}{2002} & 111 & 137 & 148 & 194 & 196 & 229 & 292 \\
\hline & 106,116 & 132,141 & 141,154 & 183,204 & 186,206 & 220,238 & 276,308 \\
\hline \multirow[t]{2}{*}{2003} & 98 & 136 & 156 & 189 & 198 & 241 & 321 \\
\hline & 93,102 & 132,140 & 149,162 & 179,199 & 188,208 & 231,251 & 303,339 \\
\hline \multirow[t]{2}{*}{2004} & 93 & 131 & 155 & 170 & 197 & 235 & 306 \\
\hline & 89,97 & 127,135 & 148,162 & 160,179 & 187,208 & 224,245 & 288,324 \\
\hline \multirow[t]{2}{*}{2005} & 94 & 131 & 157 & 167 & 184 & 244 & 285 \\
\hline & 90,98 & 127,135 & 150,164 & 157,176 & 174,194 & 234,254 & 269,302 \\
\hline \multirow[t]{2}{*}{2006} & 89 & 126 & 160 & 163 & 182 & 243 & 294 \\
\hline & 85,93 & 122,130 & 152,167 & 154,172 & 172,192 & 233,254 & 277,311 \\
\hline \multirow[t]{2}{*}{2007} & 87 & 128 & 154 & 163 & 204 & 234 & 281 \\
\hline & 83,91 & 124,131 & 147,161 & 153,173 & 193,215 & 224,244 & 265,298 \\
\hline \multirow[t]{2}{*}{2008} & 88 & 124 & 155 & 181 & 189 & 237 & 280 \\
\hline & 84,92 & 120,128 & 148,162 & 170,191 & 179,200 & 227,247 & 262,297 \\
\hline
\end{tabular}

Lower and upper $95 \%$ confidence limits shown in italics

Source: ONS 
Figure 2 Age-standardised mortality rates by three-class NS-SEC for 2001-08, women aged 25-59

England and Wales

Rate per 100,000 person years

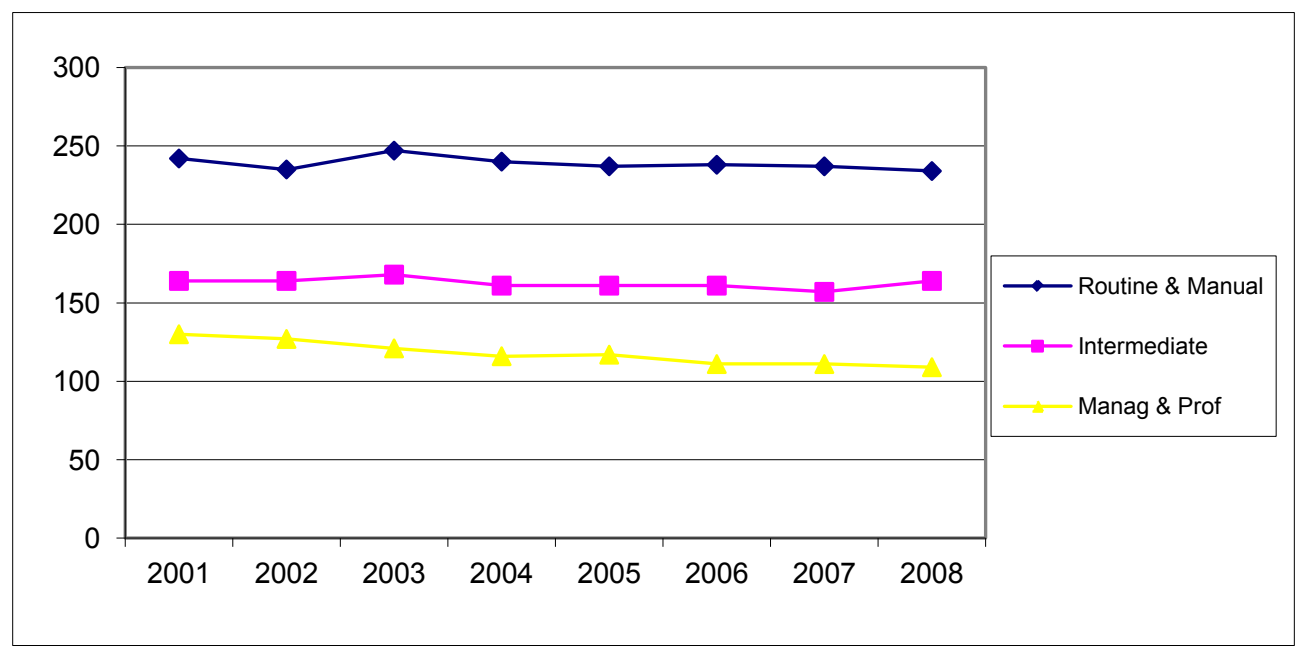

\section{Table 2 Age-standardised mortality rates by three-class NS-SEC for 2001-08, women aged 25-59}

\begin{tabular}{rrrr}
\hline 2001 & 130 & 164 & 242 \\
& 127,133 & 159,170 & 235,249 \\
2002 & 127 & 164 & 235 \\
& 124,130 & 159,170 & 228,241 \\
2003 & 121 & 168 & 247 \\
& 118,124 & 163,174 & 241,254 \\
2004 & 116 & 161 & 240 \\
2005 & 113,119 & 155,166 & 233,247 \\
& 117 & 161 & 237 \\
2006 & 114,120 & 155,166 & 230,243 \\
& 111 & 161 & 238 \\
2007 & 108,114 & 155,167 & 231,245 \\
& 111 & 157 & 237 \\
2008 & 108,114 & 152,163 & 230,244 \\
& 109 & 164 & 234 \\
\hline & 107,112 & 158,170 & 227,241 \\
\hline
\end{tabular}

Lower and upper $95 \%$ confidence limits shown in italics 
Figure 1 and Table 1 suggest that a socio-economic gradient is present in these estimates. Mortality rates for each year are in a hierarchy according to NS-SEC. Figure 1 also suggests that only Higher managerial and professional, Lower managerial and professional and the Routine class had a pronounced downward trend in mortality. No definite trend was discernible for the other classes, although Self-employed and own account workers would have had a downward trend, had it not been for the 2008 figure which may have been an outlier. Table 3 shows the average annual improvement (with standard errors) for each class.

\section{Table 3 Estimated annual decrease ${ }^{1}$ in mortality rate by NS-SEC, women aged $25-59$}

England and Wales

\begin{tabular}{llll} 
England and Wales & \multicolumn{2}{c}{ change in deaths per 100,000 per annum } \\
\hline & NS-SEC & $\begin{array}{l}\text { Estimated annual } \\
\text { decrease }\end{array}$ & Standard error \\
& & & \\
\hline 1 & Higher managerial and professional & -3.2 & $0.6^{*}$ \\
2 & Lower managerial and professional & -2.6 & $0.4^{*}$ \\
3 & Intermediate & 0.5 & 0.5 \\
4 & Self-employed and own-account & -2.7 & 1.6 \\
5 & Lower supervisory and technical & -1.6 & 1.3 \\
6 & Semi-routine & 1.5 & 0.9 \\
7 & Routine & -5.0 & $1.7^{*}$ \\
\hline
\end{tabular}

\footnotetext{
1. Annual decrease estimated from a simple linear regression against time for the period 2001-08 Source: ONS

1. Annual decrease estimated from a simple linear
- $\quad$ slope is statistically significant at the $95 \%$ level
}

The greatest annual decrease in mortality rate occurred in the Routine occupations class with a reduction of five deaths per 100,000 per year. It was followed by Higher managerial and professional occupations and Lower managerial and professional occupations, with an annual decline of around three deaths per 100,000 per annum. No other classes had a significant trend.

Table 2 and Figure 2 suggest that, for the three-class NS-SEC, Managerial and professional occupations have shown a steady decrease in mortality, while the other two groupings have experienced no significant change. This would suggest that the most advantaged experienced the greatest decline in mortality over the period $2001-08$. 


\section{Inequalities}

\section{Absolute measures}

Table 4 and Figure 3 present three measures of absolute inequality.

\section{Table 4 Measures of absolute inequalities in mortality rates of NS- SEC classes by year, women aged 25-59}

Absolute Difference of
mortality rates ${ }^{1}$ between
'Managerial and
professional' and
'Routine and manual'
class

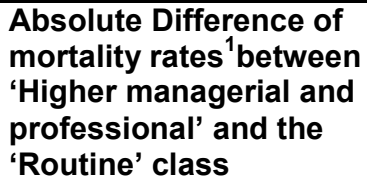

\begin{tabular}{llll}
\hline 2001 & 112 & 213 & 182 \\
2002 & 108 & 181 & 172 \\
2003 & 126 & 223 & 204 \\
2004 & 124 & 213 & 197 \\
2005 & 120 & 191 & 189 \\
2006 & 127 & 205 & 200 \\
2007 & 126 & 195 & 196 \\
2008 & 125 & 192 & 199 \\
\hline
\end{tabular}

1. Mortality rates are age-standardised to the European standard population. Numerators and denominators have been adjusted as described in the article

Source: ONS

No conclusive trend is suggested by these estimates, although the three-class NS-SEC range suggests an increase in inequality. However, an increase in the range of 18 deaths per annum occurred between 2002 and 2003, which was greater than the aggregate change over the period. This volatility reduces the confidence in the existence of a trend.

\section{Figure 3 Measures of absolute inequalities in mortality rates of NS-SEC classes by year, women aged 25-59}

Index $2001=100$

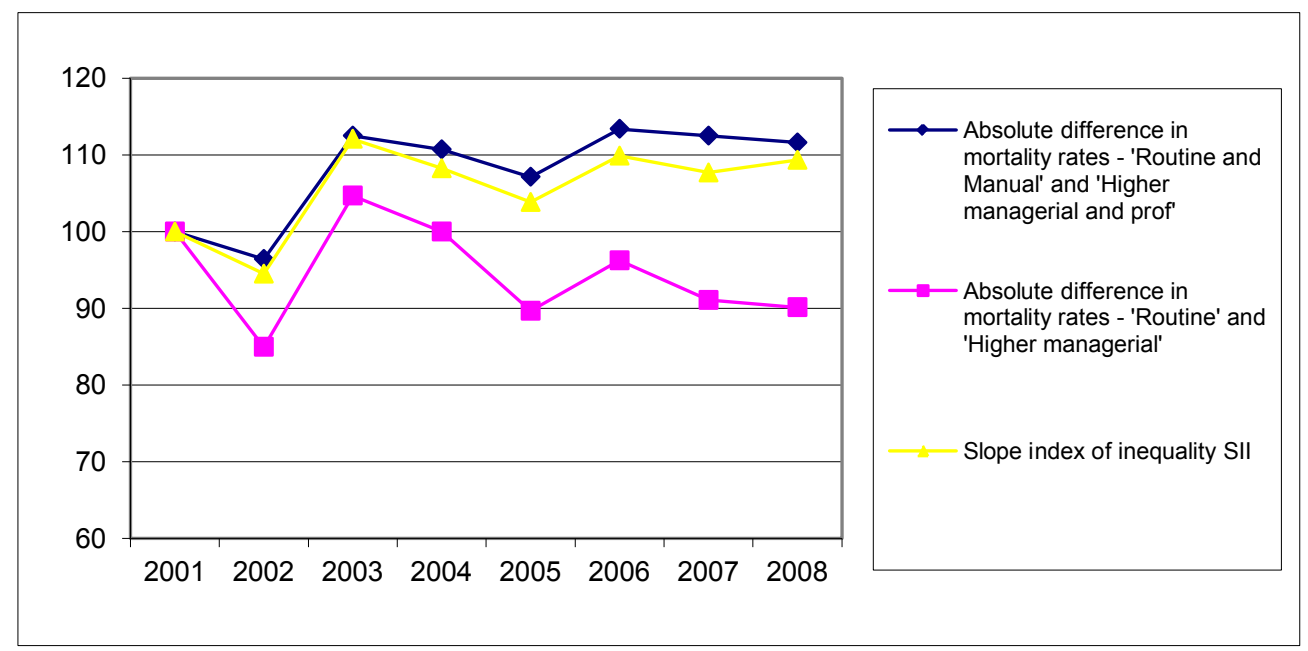


Table 5 and Figure 4 show measures of relative inequality.

Table 5 Measures of relative inequalities in mortality rates of NSSEC classes by year, women aged $25-59$

Ratio of mortality rates
between 'Managerial and
professional' and
'Routine and manual'
class

Ratio of mortality rates ${ }^{1}$ between 'Higher managerial and professional' and the 'Routine' class

\begin{tabular}{llll}
\hline 2001 & 1.9 & 3.0 & 3.3 \\
2002 & 1.9 & 2.6 & 3.2 \\
2003 & 2.0 & 3.3 & 4.2 \\
2004 & 2.1 & 3.3 & 4.2 \\
2005 & 2.0 & 3.0 & 4.0 \\
2006 & 2.1 & 3.3 & 4.6 \\
2007 & 2.1 & 3.2 & 4.5 \\
2008 & 2.1 & 3.2 & 4.6 \\
\hline
\end{tabular}

1. Mortality rates are age-standardised to the European standard population. Numerators and denominators have been adjusted as described in the article

\section{Figure 4 Measures of relative inequalities in mortality rates of NS- SEC classes by year, women aged 25-59}

Index 2001=100

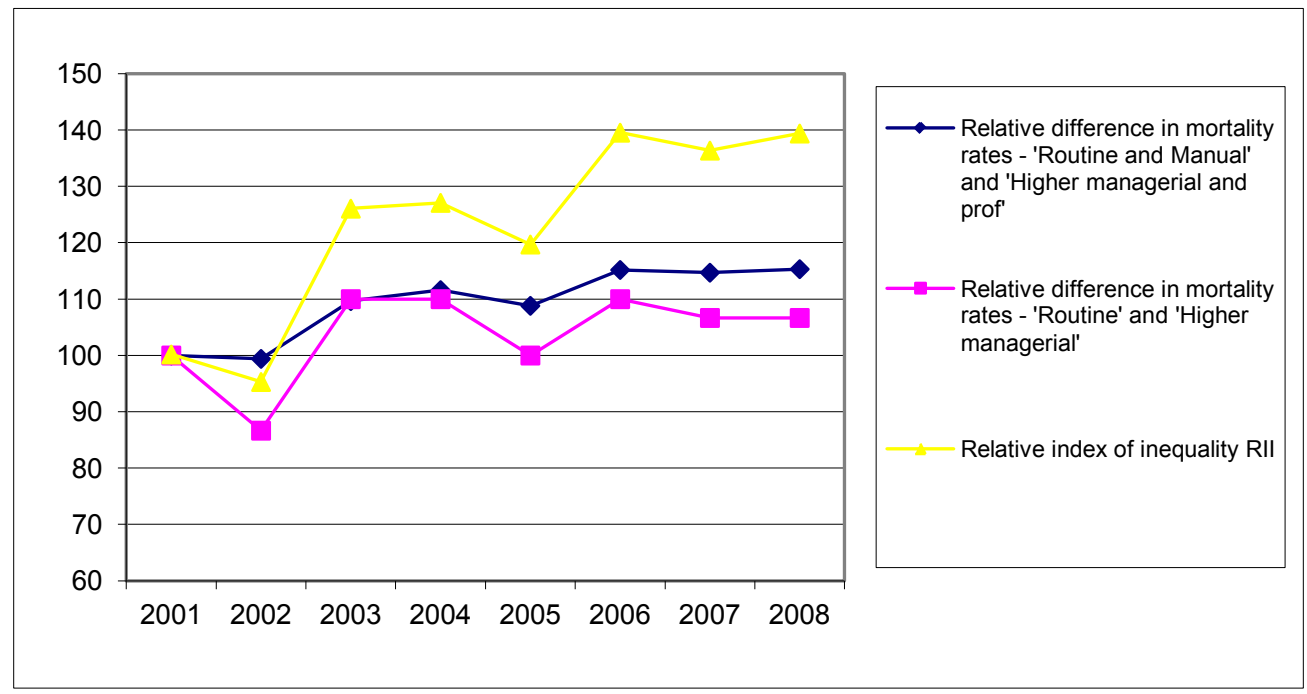


The ratio between the Routine and Manual group and the Managerial and Professional group suggests a slight increase in relative inequality. The relative index of inequality which takes into account the intervening classes suggests a greater increase in inequality. However, neither of these indicators are strictly monotonic in their trend, which again suggests a high level of variability relative to the trend. The ratio between the seven-class Routine class and the most advantaged Higher managerial and professional class shows no trend. The sharp reduction in inequality in 2005 arises from the decreased mortality rate of the Routine NS-SEC classes in 2005 as a result of a 4 per cent decrease in deaths for this class in a single year. The authors cannot find an empirical explanation for this change.

\section{Figure 5 Three-year simple moving averages of age-standardised mortality rates by NS-SEC, women 25-59, 2001-08}

England and Wales

Rate per 100,000 person years

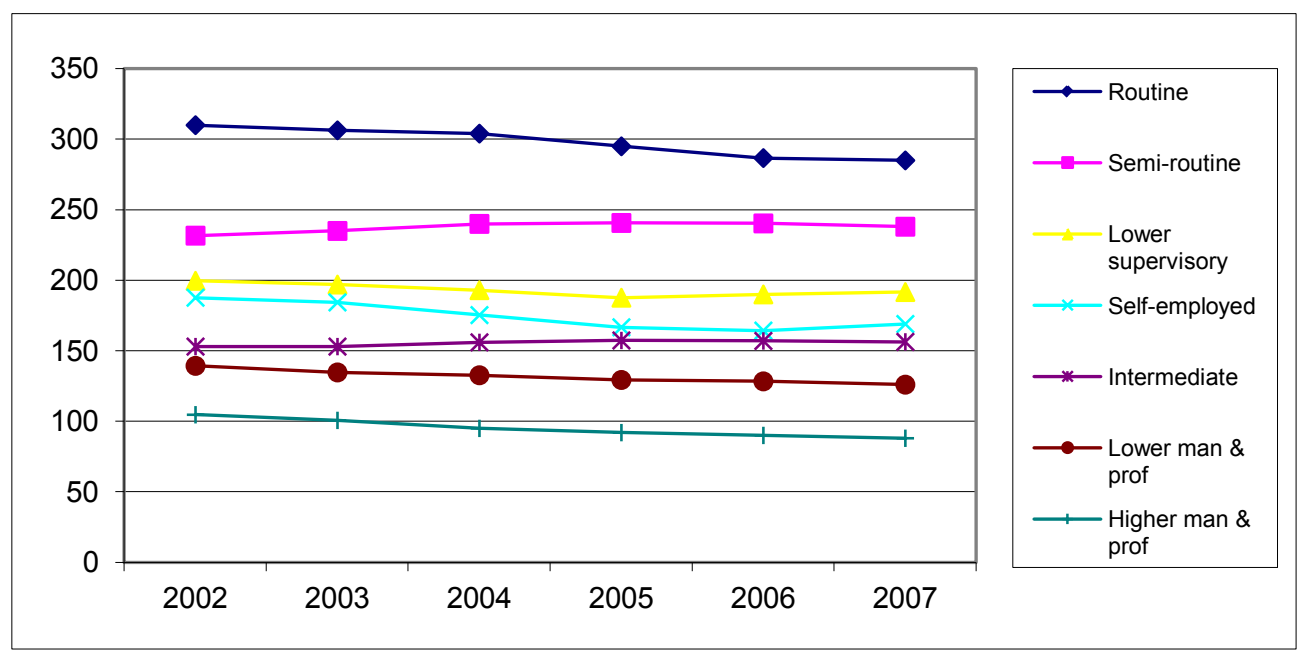

Figure 5 shows a clearer picture of trends by smoothing the annual figures to show a three-year centred moving average. It can be seen more clearly here that there is a trend toward decreased mortality for Higher and Lower managerial and professional occupations and Routine occupations. Small employers and own account workers show some sign of a decline in mortality.

An unexpected result is the apparent increase in mortality among the Semi-routine class. This is not a statistically significant result, but the relatively poor recent trend for this class is a matter for concern. 


\section{Discussion}

The results suggest that, over the period 2001 to 2008, there has been a decrease in overall mortality rates for women but not for all classes. Both Higher managerial and professional and Lower managerial and professional occupations showed a steady and significant decline in mortality rates over the period 2001-08, as did Routine occupations. The intervening classes did not show any significant trend over the period.

For both absolute and relative measures of inequality, the use of the range between the extremes of the class schema, between Higher managerial and professional and Routine classes, proved too volatile to show any trend. By contrast, the more aggregated three-class condensed NS-SEC did suggest an increase in inequalities in relative terms.

The relative index of inequality also showed an increase in inequality, but the absolute index showed no discernible trend.

One of the most surprising results is the apparent rise in mortality for the Semi-routine class. The reason for this was a rise in total deaths of 5 per cent in this class for this age group, while population remained fairly static. This was compared with a fall in aggregate deaths across all classes of about 6 per cent. This increase in deaths, particularly in the upper age groups of the range, remains unexplained. A general comparison with longer-term trends in female life expectancy, (Johnson, 2011) suggested that the pattern for the most advantaged classes (Higher managers and professionals and Lower managers and professionals) was reflected in the results of the current study, with these classes experiencing the greatest growth in life expectancy over twenty years and the greatest decline in mortality between 2001 and 2006 . However, there is no indication in the life expectancy estimates to suggest a poor trend performance in mortality rate for Semi-routine occupations, nor is there evidence of a greater than average recent improvement in the mortality of the Routine class, as suggested by the results from the current study. It should be remembered that life expectancy covers deaths at all ages whereas the current study focuses only on deaths at working age. For the year 2008, female deaths between age 25 and 59 constituted only 8 per cent of total female deaths above the age of 25 .

\section{Comparison with the results for men}

While comparison with the results for men is complicated by the enforced omission of the age group 60-64, (where naturally a higher rate of mortality occurs than between 25 and 59), the results show some major differences to those obtained for men (Langford and Johnson, 2010).

Firstly, the overall rate of decline in mortality rate for women was less than for men (less than two deaths per 100,000 per annum compared with six deaths per 100,000 per annum for men in the age group 25-64). Women's mortality in general is much lower than men's on average at these ages, but it appears that men are 'catching up'. For men, all NS-SEC classes showed a significant trend decline in mortality over the period 2001-08. By contrast, it appears from the results presented here that the reduction in female mortality at working age is sufficiently small that the variation from year to year obscures the trend in all but the three classes referred to above. 
Absolute measures of inequality were greater for men, and declining over time. For women, the absolute measures did not exhibit a discernible trend. Relative measures of inequality were of a similar magnitude and pattern for men and women. Inequality by these measures increased for both, but was slightly smaller on all measures for women. This pattern of greater absolute inequality for men but similar levels of relative inequality between the sexes has been found across developed economies (Mustard and Etches, 2003). At the very low levels of female mortality at ages studied, it is more likely that relative measures will show an increasing trend in inequality than absolute ones (Scanlan (2000), Eikemo et al (2009)).

Where trends for women were apparent in the current study it appears that the most advantaged have tended to improve their position compared with the other classes. The only exception is in the absolute improvement of the Routine class which showed the greatest mean reduction in mortality rate per year of all classes, as was the case for men in the earlier article.

There are a number of potential explanations which have been advanced for generally lower observed mortality differences by socio-economic class for women than for men. One is that women are exposed to fewer occupational hazards than men in the same socio-economic class (OPCS, 1978 ch 3). However, those analyses which differentiated single women using their own socio-economic classification, have found similar social gradients to those for men (Moser et al,1990, Koskinen S \& Martelin T, 1994, Langford \& Johnson, 2009), see Figure A3. It therefore seems unlikely that direct occupational hazards are a major cause of within class mortality differentials.

If the woman's class is determined by her husband using the 'combined' approach to socioeconomic classification, NS-SEC is measuring only her life chances based on the assumed socio-economic location of the household. While this type of approach has been found to produce inequalities similar to those for men (Sacker A et al, 2006, Langford and Johnson 2009), it is to be expected that the social gradient based on this measure would be diluted by the indirect nature of the classification.

The combination of some women who were economically inactive with those who had an occupation of their own in the same NS-SEC class may further reduce the distinctiveness of class definition. If the data had permitted, it may have been found that those women who were not economically active would exhibit a higher death rate than those in the same NS-SEC class who had been assigned to that class based on their own occupation. For example, Moser et al (1990) found that the group of women classified as not in paid employment and married to men in manual social classes had the highest death rate of all cross-classifications of spouses, except where neither spouse was in employment.

In the current study, data for 2001 suggested that 42 per cent of female deaths were assigned to an NS-SEC class based on their own occupation, while 39 per cent were assigned based on their husband's occupation. (The remaining 19 per cent could not be assigned based on death registration data). Approximately 60 per cent of those assigned via the husband's occupation were women with no recorded occupation of their own. There was a wide variation in these percentages across classes. For example, 81 per cent of deaths assigned to the 'Intermediate' class were based on the woman's own class, while only 26 per cent of those assigned to 'Higher managerial and professional' were. 
A more straightforward reason for smaller inequalities among women is that many of the causes of death with very steep social gradients, such as lower respiratory diseases and circulatory disease are more prevalent in men than women (Mackenbach et al, 1999, Koskinen and Martelin, 1994, White et al, 2008, Langford et al, 2009). By contrast, breast cancer mortality has a negligible social gradient.

\section{Suitability of the LFS-based measures for monitoring health inequalities.}

The corresponding study on men (Langford and Johnson, 2010), stated that 'annual trends in inequalities in mortality at the national level can be effectively monitored using LFS-based measures'. The current study has probably demonstrated the limits to this method, particularly when incremental changes from year to year are relatively small. For three out of the seven analytic NS-SEC classes, there was no statistically significant trend. More importantly, there appeared to be volatility or 'noise' from year to year which in most cases outweighed the trend effect. It must be acknowledged that detecting trends at very low levels of mortality is difficult. A recent longitudinal study of England and Wales found clear rising trends in female life expectancy for each NS-SEC class, but in individual years, life expectancy for a particular class might fall, (Johnson, 2011). Further, the LS study used all ages including the very elderly where there were much higher age-specific mortality rates. The current study focused on an age range (25-59) where the LS would have shown a similar degree of volatility from year to year (though still a clear long-term trend).

Retrospective changes in LFS populations over time through reweighting of the survey would also have a small but detectable change in estimates which would make them subject to revision. Given these qualifications it seems feasible to use the LFS-based estimates for indicators of health at national level, provided it is recognised that a figure for any given year may be an aberration.

\section{Limitations of the analysis}

Owing to the sparse recording of women's occupations at death after normal retirement age, it was necessary to restrict the analysis to women aged 25-59, accounting for only 8 per cent of the deaths of women over the age of 25.

The LFS is the main source of the population estimates that was used to produce denominators for the estimates of mortality rates presented in this article. As a survey the LFS can encounter changes due to methodological improvement and to maintain consistency of its published aggregates, and this may have effects on the presented results. Boosts to LFS sample size were introduced a number of times over the period 2001-2008, but this should not have an effect on estimates of mortality rates. It is possible, however, that changes to LFS response rates do have an effect. The response rate to the LFS changed from 69 per cent in 2001 to 60 percent in the first quarter of 2008 with high refusal rates in London and in flats and mobile accommodation (Barnes et al, 2008). However, the LFS weighting system should correct for this and maintain the LFS population consistent with the latest official population estimates. With the exception of 2001, the LFS weights calculated in 2010 have been used throughout this analysis and, as a result, the estimates should be consistent across time. For 2001, 2010 weights were not available, and so 2007 weights were used. Comparison of the population by NS-SEC in other years where both 
sets of weights were available suggested that this would not have had a substantial effect on the results for 2001. For the years 2002 and 2003, the LFS sample for March of the year in question to February of the following year had to be used, owing to a lack of annual data from January to December for these years weighted by 2010 weights.

The combined NS-SEC was used in this article to compensate for the very sparse recording of women's occupations at death and the difficulty in. classifying women's socio-economic position based on occupation alone. There are conceptual problems with the use of a combined NS-SEC since theoretically, NS-SEC is based on the employment relations status of the individual. Using the most advantaged NS-SEC of a married couple implies the assumption that one can use the most advantaged labour force status of two marriage partners as a proxy for the life-chances of both. Naturally this is not always the case, but it is felt that this provides a more accurate classifier for most women than using simply their own occupation-based class. There may also be biases arising from the fact that some occupations have fewer men so that, for example, 'Lower technical' will more often be taken from a male partner's occupation, while 'intermediate' may more often be the woman's occupation. In addition, the NS-SEC classification at death provides only a snapshot of a woman's class location and cannot reflect the potential accumulation of advantage and disadvantage over the lifecourse.

A number of adjustments were made to the raw data during the course of the calculations.

- Following the practice of earlier studies, in particular Langford and Johnson, (2009), owing to the under-recording of occupation at death of women, adjustments were made to the numbers of deaths by NS-SEC. These adjustments were based on an analysis in an earlier study of 158 female deaths of members of the ONS Longitudinal Study who had no occupation recorded at death in the years 2001-04. It was found that approximately 70 per cent of these women had an occupation according to the 2001 Census. The percentage distribution of these 'unclassified' women across NS-SEC classes was used throughout the study and assumed to be fixed throughout. There was a smaller reallocation of NS-SEC class 3 deaths to NS-SEC class 2 , since it was discovered that a substantial number of deaths inaccurately failed to note the supervisory status of the deceased (see White et al, 2007).

- Populations by NS-SEC were also adjusted to take account of health selection. This is where those without a recorded occupation have been selected out of the workforce for health reasons. Again, in an earlier study using the LS, a certain proportion of people of working age who did not have an occupation at the 2001 Census but did have one in 1991 were assumed to be 'selected out'. (Langford and Johnson, 2009). The proportions obtained in terms of reallocation across NS-SEC classes were the same as for the estimates obtained using 2001 Census data for population denominators. These proportional reallocations remained constant throughout the study period. 
There is a case for not making adjustments, since they add to the complexity of the analysis. However, health selection effects are well known and to ignore them would invite a known bias. Because of this concern, a sensitivity analysis was carried out whereby the raw deaths and LFS population estimates by age band and NS-SEC were used to estimate mortality rates. While substantial differences occurred for particular classes in particular years, the overall pattern remained remarkably similar to those described above, and none of the observations or conclusions would have been substantively altered as a result.

Another assumption made was that those living in communal establishments and not counted by the LFS did not make a substantive difference in the distribution across NS-SEC analytic classes for women aged 25-59. This would appear reasonable, since deaths at communal establishments were less than 2 per cent of all deaths for women under age 60 and there was no identifiable pattern among analytic NS-SEC classes in the proportion of deaths which were at communal establishments.

\section{Conclusions and Recommendations}

This study has attempted to estimate the annual change in inequality in mortality rates by NSSEC for women aged 25-59 in the period 2001-08 using the LFS to estimate populations by age band and NS-SEC. The estimates suggested that there was a statistically significant downward trend in mortality for Higher managerial and professional occupations, Lower professional and managerial occupations and for Routine occupations. Intervening classes did not exhibit a significant trend. In particular, the volatility from year to year obscured the trend for certain classes.

Both absolute and relative indicators of inequality were used. The absolute difference measures showed no discernible trend. The relative difference measures showed a slight increase in inequality, except for the range between Higher managerial and professional and Routine occupations. Routine occupations had the greatest mean reduction in mortality rates per year (approximately five deaths per 100,000 population per annum). Absolute differences in inequality were substantially less than they were for men and relative differences were slightly smaller, but of a similar magnitude.

Mortality of women aged $25-59$ is very low and therefore less likely to exhibit a downward trend than deaths at older ages. This makes it difficult to identify trends. The annual volatility apparent in this data and the range of the confidence intervals of the estimates suggest that this analysis is at the limit of the capability of the LFS sample to provide population denominators by class.

\section{Acknowledgements}

The authors would like to thank the Labour Force Survey branch of the ONS for making available the relevant data and for guidance on its use. Any errors in the interpretation of the data are the responsibility of the authors. 


\section{References}

The Acheson Report (1998) Independent Inquiry into Inequalities in Health, TSO:London

The Black Report (1992) in Townsend P and Davidson N (eds) Inequalities in Health. The Black Report and The Health Divide. Penguin Books, London

Barnes W, Bright G and Hewat C (2008) 'Making sense of Labour Force Survey response rates', Economic and Labour Market Review 2(12) pp 32-41

Blane D, Davey Smith G and Bartley M (1993) 'Social selection - what does it contribute to social class differences in health', Sociology of health and illness 15 pp 2-15.

Bostrom G and Rosen M (2003) 'Measuring social inequalities in health - politics or science?' Scand J Public Health 31 pp 211-215

Chandola T, Bartley M, Wiggins R and Schofield P (2003) 'Social inequalities in health by individual and household measures of social position in a cohort of healthy people', Journal of Epidemiology and Community Health 57, 56-62.

Department of Health (2003) Tackling Health Inequalities: A programme for action, Department of Health: London.

Department of Health (2009) Tackling Health Inequalities:2006-08 Policy and Data Update for the 2010 National Target, Department of Health: London.

Eikemo T, Skalicka V and Avendano M (2009) 'Variations in relative health inequalities: are they a mathematical artefact?' International Journal for Equity in Health 8:32

Erikson R (1984) 'Social class of men, women and families', Sociology, 18, 500-14

Fox A, Goldblatt P and Jones D (1985) 'Social class mortality differentials: artefact, selection or life circumstances?', Journal of Epidemiology and Community Health 39 pp 01-08.

Goldblatt P (1990) "Mortality and alternative social classifications" in Goldblatt P (Ed) Longitudinal Study (Mortality and Social Organisation)

Johnson B (2011) 'Deriving trends in life expectancy by the National-Statistics Socio-economic Classification using the ONS Longitudinal Study', Health Statistics Quarterly 49 pp 9-52

Johnson B and Langford A (2010) 'Intercensal denominators-feasibility of using the Labour Force Survey to estimate mortality rates by NS-SEC' , Health Statistics Quarterly 45 pp 3-27

Koskinen S and Martelin T (1994) 'Why are socio-economic mortality differences smaller among women than among men?', Social Science and Medicine 38, 1385-96.

Kunst A and Mackenbach J (1994) 'Measuring Socio-economic inequalities in health'. World Health Organisation, Copenhagen 
Langford A and Johnson B (2010) 'Trends in social inequalities in male mortality, 2001-08. Intercensal estimates for England and Wales', Health Statistics Quarterly 47 pp 5-32

Langford A and Johnson B (2009) 'Social inequalities in adult female mortality by the National Statistics Socio-economic Classification, England and Wales, 2001-03', Health Statistics Quarterly 42 pp 6-21

Mackenbach J P, Kunst A E, Groenhof F, Borgan J K, Costa G, Faggiano F, Jozan P, Leinsalu M, Martikainen P, Rychtarikova J and Valkonen T (1999) 'Socio-economic Inequalities in Mortality Among Women and Among Men: An International Study', American Journal of Public Health 89 1800-06.

Mackenbach J P and Kunst A E (1997) 'Measuring the magnitude of socio-economic inequalities in health: an overview of available measures illustrated with two examples from Europe', Soc Sci Med 44(6) pp 757-771

The Marmot Review (2010) Fair society healthy lives (The Marmot Review), The Marmot Review, London

Moser K, Pugh H and Goldblatt P (1990) 'Mortality and the social classification of women' in Goldblatt P (ed), Longitudinal Study (Mortality and Social Organisation), Her Majesty's Stationery Office: London.

Mustard C A and Etches J (2003) 'Gender differences in socioeconomic inequality in mortality', Journal of Epidemiology and Community Health 57 pp 974-980.

Office for National Statistics (2009) The Labour Force Survey User Guide Volume 1 Background and Methodology. Available on the Office for National Statistics website at: www.ons.gov.uk/ons/guide-method/user-guidance/labour-market-statistics/index.html

Office for National Statistics (2008) The ONS Longitudinal Study website: www.ons.gov.uk/ons/about-ons/who-we-are/services/longitudinal-study/index.html

Office for National Statistics(2007) The National Statistics Socio-economic Classification on-line edition. Available on the Office for National Statistics website : www.ons.gov.uk/ons/guide$\underline{\text { method/classifications/archived-standard-classifications/ns-sec/index.html }}$

Office for Population Census and Surveys (1978) Occupational Mortality 1970-72, Chapter 3, Series DS No 1, HMSO: London

Rose D and Pevalin D (Eds) (2003) A Researcher's Guide to the National Statistics Socioeconomic Classification. SAGE Publications Ltd.

Scanlan J P (2000) 'Race and Mortality', Society 37(2) pp 29-35

Sacker A Firth D, Fitzpatrick R, Lynch K and Bartley M (2000) Comparing health inequality in men and women: prospective study of mortality 1986-96, British Medical Journal 320, pp 130307 
Skalicka V and Kunst A (2008) Effects of spouses' socioeconomic characteristics on mortality among men and women in a Norwegian longitudinal study' Social Science and Medicine,66 No 9 pp 2033-47

Sergeant J and Firth D (2006) 'Relative index of inequality: definition, estimation and inference' Biostatistics 7:2 pp 213-224

Thomas M and Aubrey-Smith S-A (2008) 'The impact of Labour Force Survey and Annual Population Survey reweighting' Economic and Labour Market Review 2(12) pp 56-63

White C, Chow YH and van Galen F (2003) 'Trends in social class differences in mortality by cause, 1986 to 2000', Health Statistics Quarterly 20 pp 25-37

White C, Edgar G and Siegler V (2008) 'Social inequalities in male mortality for selected causes of death by the National Statistics Socio-economic Classification, England and Wales, 2001-03', Health Statistics Quarterly 38, 19-31. Available on the Office for National Statistics website at: www.ons.gov.uk/ons/rel/hsq/health-statistics-quarterly/no--38--summer-2008/social-inequalitiesin-male-mortality-for-selected-causes-of-death-by-the-national-statistics-socio-economicclassification.pdf

White C, Glickman M, Johnson B and Corbin T (2007) 'Social inequalities in adult male mortality by the National Statistics Socio-economic Classification, England and Wales, 2001-03', Health Statistics Quarterly 36 pp 6-23 Available on the Office for National Statistics website at: www.ons.gov.uk/ons/rel/hsq/health-statistics-quarterly/no--36--winter-2007/social-inequalities-inadult-male-mortality-by-the-national-statistics-socio-economic-classification--england-and-wales-2001-03.pdf

Wright M and Phillips C (2011) 'Labour Force Survey: reweighting to 2010 population estimates' Household and Labour Market Division, ONS 


\section{Appendix A}

\section{Health selection adjustments for LFS data}

The concept of 'occupation' used to derive socio-economic class for the purpose of estimating mortality rates in successive Registrar General's decennial supplements, is that in which the person is currently engaged or most recently was engaged, if not currently employed or economically active. This is partly because using only current occupation tends to understate those who are usually employed and makes classification more subject to macroeconomic fluctuations. In addition, death registration of necessity uses a definition which extends back in time. Thus occupation in this context is not restricted to the employed or even to the economically active. Most importantly, those in the most disadvantaged classes are less likely than the more advantaged to report a former occupation if sick, and this may lead to biased estimates if not adjusted (OPCS, 1978).

In the published estimates using census-based denominators, an adjustment was made to counteract a potential selection effect brought about because some of those in poor health may have been selected out of the labour market. This adjustment was made using the ONS Longitudinal Study to estimate the proportion of those with no recorded occupation and therefore no analytic NS-SEC class in 2001, but who had a recorded occupation in 1991. The 1991 NSSEC distribution of those in each age group unclassified at 2001 was used to redistribute population to the analytic NS-SEC classes. In order to make results using the LFS consistent with the published ones based on the census, it was necessary to imitate the adjustments undertaken on the census-based denominators using the published adjustment for those with no occupation recorded in 2001. The adjustment process first estimates the number of people which should be redistributed from the residual to the analytic classes, and then allocates to classes using the same distribution pattern as the census-based estimates.

\section{Illustrative example of derivation of populations by age and NS-SEC using the LFS counts and ONS mid-year populations}

The process of translating the raw LFS counts into population estimates comparable with the published census-based figures is shown for 2001 in Table A1. 


\section{Table A1 Raw LFS population counts by NS-SEC and steps involved in reallocating residual population, women aged 25-59, 2001}

\begin{tabular}{|c|c|c|c|c|c|c|}
\hline \multirow[t]{2}{*}{ England and Wales } & & & & \multicolumn{3}{|c|}{ Thousands } \\
\hline & $\begin{array}{c}\text { Total of } \\
\text { analytic } \\
\text { groups } \\
\text { Sum }(1.1-7)\end{array}$ & $\begin{array}{c}\text { ONS } \\
\text { mid-year } \\
\text { population }\end{array}$ & $\begin{array}{l}\text { Unallocated } \\
\text { population }\end{array}$ & $\begin{array}{c}\text { Proportion } \\
\text { residual in } \\
\text { optimised } \\
\text { table }^{2}\end{array}$ & $\begin{array}{c}\text { Final } \\
\text { residual }\end{array}$ & $\begin{array}{l}\text { others for } \\
\text { reallocating } \\
\text { across } \\
\text { analytic } \\
\text { groups }\end{array}$ \\
\hline
\end{tabular}

\begin{tabular}{|c|c|c|c|c|c|c|c|c|c|c|c|c|c|c|}
\hline & \multicolumn{8}{|c|}{$\begin{array}{l}\text { LFS population counts by NS-SEC analytic } \\
\text { class, women, } 2001\end{array}$} & \multirow[b]{2}{*}{ a } & \multirow[b]{2}{*}{ b } & \multirow[b]{2}{*}{$c=b-a$} & \multirow[b]{2}{*}{ d } & \multirow[b]{2}{*}{$e=b \times d$} & \multirow[b]{2}{*}{$f=c-e$} \\
\hline & 1.1 & 1.2 & 2 & 3 & 4 & 5 & 6 & 7 & & & & & & \\
\hline \multicolumn{15}{|l|}{ Ageband } \\
\hline $25-29$ & 94 & 147 & 512 & 273 & 60 & 125 & 240 & 120 & 1571 & 1745 & 174 & 0.080 & 139 & 35 \\
\hline $30-34$ & 187 & 194 & 583 & 267 & 107 & 162 & 241 & 119 & 1860 & 2033 & 173 & 0.049 & 99 & 74 \\
\hline $35-39$ & 223 & 199 & 597 & 254 & 154 & 165 & 223 & 120 & 1935 & 2082 & 147 & 0.038 & 78 & 69 \\
\hline $40-44$ & 194 & 174 & 530 & 234 & 142 & 148 & 195 & 103 & 1720 & 1853 & 133 & 0.032 & 59 & 74 \\
\hline $45-49$ & 169 & 157 & 494 & 201 & 134 & 142 & 167 & 91 & 1555 & 1670 & 115 & 0.028 & 47 & 68 \\
\hline $50-54$ & 159 & 154 & 502 & 211 & 156 & 162 & 207 & 105 & 1656 & 1801 & 145 & 0.023 & 42 & 103 \\
\hline $55-59$ & 110 & 109 & 366 & 196 & 143 & 148 & 201 & 105 & 1378 & 1520 & 142 & 0.025 & 37 & 105 \\
\hline Total & 1135 & 1134 & 3583 & 1636 & 897 & 1051 & 1474 & 763 & 11675 & 12705 & 1029 & & 501 & 528 \\
\hline
\end{tabular}

1 ONS mid-year population estimates for 2001

2 Langford A and Johnson B (2009) 'Social inequalities in adult female mortality by the National Statistics Socio-economic

Classification, England and Wales, 2001-03, Health Statistics Quarterly,42,p6-21

3 Totals may not agree precisely with the numbers in the body of the table owing to rounding

The LFS based estimates for each NS-SEC analytic class are shown on the left-hand side of the table and the totals for each age group are shown in column a. The ONS mid-year population totals for 2001 are in column b and the difference (the 'unallocated' population), in column c.

In order to approximate the optimised estimates, it is necessary to simulate the transfer from the unallocated populations to the NS-SEC analytic classes, which was undertaken on the published census data using the health selection adjustment.

Firstly the proportion of the population in each age group which was to be assigned to the residual NS-SEC classes was set equal to that in the census-based 'optimised populations'.(column d in Table A1). These proportions were multiplied by the ONS mid-year populations to obtain the numbers in the residual categories (column e). The remainder of the unallocated population is obtained by subtracting column e from column c. 
Thus for example, the number unclassified aged 25-29 in the optimised population estimates was 8 per cent of the total population Thus the population (in thousands) in the residual is $1745 \mathrm{x}$ $8 \%=139$ (rounded to thousands). The number available for reallocation is therefore equal to the population for the age group (1745) less the NS-SEC analytic group population estimated from the LFS estimates (1571) less 139 (equals 35).

The resultant population is then reallocated across NS-SEC classes according to the proportions estimated from the gain in person-years by each NS-SEC analytic group from the health selection adjustment in the published study using census-based denominators, (Langford and Johnson (2009), Social Inequalities in adult female mortality by NS-SEC, England and Wales, 2001-03, Health Statistics Quarterly, No. 42. Table A2 shows these revised population counts.

\section{Table A2 Revised population counts by NS-SEC after adjustments, women aged 25-59, 2001}

Thousands

\begin{tabular}{|c|c|c|c|c|c|c|c|c|c|c|}
\hline \multirow[b]{3}{*}{ 25-29 } & \multicolumn{8}{|c|}{ LFS population counts by NS-SEC analytic class } & \multirow[b]{2}{*}{ Residual $^{1}$} & \multirow[b]{2}{*}{$\begin{array}{l}\text { Total } \\
\text { ulation }\end{array}$} \\
\hline & 1.1 & 1.2 & 2 & 3 & 4 & 5 & 6 & 7 & & \\
\hline & 94 & 147 & 513 & 282 & 59 & 126 & 256 & 130 & 139 & 1745 \\
\hline $30-34$ & 187 & 194 & 586 & 282 & 105 & 164 & 274 & 143 & 99 & 2033 \\
\hline $35-39$ & 224 & 200 & 601 & 269 & 154 & 168 & 248 & 141 & 78 & 2082 \\
\hline $40-44$ & 196 & 175 & 536 & 250 & 142 & 150 & 220 & 125 & 59 & 1853 \\
\hline $45-49$ & 171 & 157 & 505 & 215 & 137 & 145 & 185 & 109 & 47 & 1670 \\
\hline $50-54$ & 162 & 156 & 522 & 243 & 161 & 161 & 229 & 124 & 42 & 1801 \\
\hline $55-59$ & 110 & 109 & 387 & 222 & 146 & 148 & 234 & 126 & 37 & 1520 \\
\hline Total & 1144 & 1138 & 3650 & 1763 & 904 & 1062 & 1646 & 898 & 501 & 12705 \\
\hline
\end{tabular}

1 As per Table A1

2 ONS mid-year population estimates for 2001, as per Table A1

3 The effect of rounding will mean that some totals are not a precise sum of the figures shown 


\section{Table A3 2001-08 Study number of deaths by combined ${ }^{1}$ NS-SEC classification, women aged 25-59}

England and Wales

\begin{tabular}{rrrrrrrrrrr}
\hline \multicolumn{10}{c}{ NS-SEC analytic classes } \\
\hline Year & 1.1 & 1.2 & 2 & 3 & 4 & 5 & 6 & 7 & Unoccupied $^{2}$ & Total $^{2}$ \\
2001 & 930 & 1136 & 4439 & 2422 & 1688 & 1910 & 2844 & 2291 & 4070 & 21730 \\
2002 & 1066 & 1201 & 4382 & 2319 & 1761 & 1818 & 2919 & 2077 & 4096 & 21639 \\
2003 & 991 & 1090 & 4412 & 2456 & 1767 & 1736 & 2984 & 2156 & 4337 & 21929 \\
2004 & 931 & 1177 & 4384 & 2398 & 1564 & 1684 & 2912 & 1956 & 4223 & 21229 \\
2005 & 928 & 1188 & 4396 & 2450 & 1503 & 1526 & 3035 & 1874 & 4354 & 21254 \\
2006 & 938 & 1136 & 4298 & 2397 & 1477 & 1426 & 3060 & 1910 & 4309 & 20951 \\
2007 & 930 & 1167 & 4374 & 2330 & 1411 & 1619 & 2977 & 1790 & 3889 & 20487 \\
2008 & 964 & 1109 & 4203 & 2315 & 1532 & 1423 & 3000 & 1728 & 4216 & 20490 \\
Total & 7678 & 9204 & 34888 & 19087 & 12703 & 13142 & 23731 & 15782 & 33494 & 169709 \\
& & & & & & & & & &
\end{tabular}

$1 \mathrm{~A}$ combined classification where the most advantaged of the women's NS-SEC class and that of her husband was used. If a woman was not married then her own classification was used.

2 Including never worked, long term unemployed, full time students, occupations inadequately described, not classifiable for other reasons.

\section{Table A4 2001-08 LFS Study populations (person years at risk) by} combined $^{1}$ NS-SEC classification, women aged $25-59$

\begin{tabular}{lrrrrrrrrrr}
\hline & \multicolumn{10}{c}{ NS-SEC analytic classes } \\
\hline Year & 1.1 & 1.2 & 2 & 3 & 4 & 5 & 6 & 7 & Unoccupied $^{2}$ & Total $^{2}$ \\
2001 & 1135 & 1134 & 3583 & 1636 & 897 & 1051 & 1474 & 763 & 987 & 12661 \\
2002 & 1205 & 1120 & 3629 & 1643 & 861 & 1024 & 1475 & 749 & 993 & 12700 \\
2003 & 1228 & 1176 & 3698 & 1628 & 880 & 970 & 1416 & 703 & 1015 & 12714 \\
2004 & 1271 & 1213 & 3731 & 1588 & 885 & 952 & 1417 & 684 & 1021 & 12762 \\
2005 & 1281 & 1223 & 3766 & 1579 & 881 & 944 & 1394 & 676 & 1044 & 12788 \\
2006 & 1283 & 1285 & 3785 & 1538 & 870 & 912 & 1404 & 672 & 1092 & 12841 \\
2007 & 1300 & 1300 & 3801 & 1520 & 853 & 888 & 1431 & 661 & 1057 & 12812 \\
2008 & 1310 & 1301 & 3745 & 1526 & 839 & 865 & 1467 & 670 & 1068 & 12789 \\
Total & 10013 & 9752 & 29738 & 12657 & 6967 & 7606 & 11479 & 5577 & 8277 & 102067 \\
& & & & & & & & & &
\end{tabular}

$1 \mathrm{~A}$ combined classification where the most advantaged of the women's NS-SEC class and that of her husband was used. If a woman was not married then her own classification was used.

2 Including never worked, long term unemployed, full time students, occupations inadequately described, not classifiable for other reasons. 